\title{
Prostitución voluntaria o forzada. Una contribución al debate
}

\author{
Enric Sanchis \\ Universitat de València. Departament de Sociologia i Antropologia Social \\ enric.sanchis@uv.es
}

Recibido: 29-03-2010

Aceptado: 02-12-2010

\section{Resumen}

La tesis abolicionista de que nadie puede elegir libremente vender su cuerpo ha sido cuestionada por quienes reclaman el reconocimiento de derechos laborales para los trabajadores del sexo, lo cual ha dado lugar a una encendida polémica sobre el carácter voluntario o forzado de la prostitución. Los testimonios de veintitrés mujeres (incluyendo cinco ex prostitutas), recogidos mediante entrevistas en profundidad, sugieren que todas ellas están situadas en un punto intermedio del continuum que va desde la coerción criminal hasta la opción vocacional. Los pasajes relativos específicamente al itinerario de acceso a este mundo permiten distinguir tres tipos de prostitución en función del grado de constricción estructural que soportan: prostitución clásica, económica en sentido estricto y voluntaria, si bien las fronteras que delimitan estos tipos no pueden trazarse con precisión. Queda, una vez más, en evidencia la diversidad que caracteriza a la prostitución, que también afecta a las formas de practicarla: a tiempo completo o parcial, de manera recurrente u ocasional. En España, las políticas de intervención asumen el estereotipo de la prostituta víctima de explotación impuesto por el punto de vista abolicionista y no tienen en cuenta esta diversidad. Ello puede provocar efectos no deseados, entre otros, el de empeorar las condiciones de vida y de trabajo de las mujeres involucradas en la prostitución.

Palabras clave: coerción; constricción estructural; trabajo sexual; abolicionismo; derechos laborales; políticas públicas; España.

\footnotetext{
Abstract. Prostitution voluntary or forced. A contribution to the debate

The abolitionist thesis that no one can freely choose to sell their body has been challenged by those who advocate the recognition of employment rights for sex workers. Underlying both positions is a fierce argument about the voluntary or forced nature of prostitution. Evidence from in-depth interviews with 23 women (including five ex-prostitutes) suggests they are located at a midway point on the continuum that ranges from prostitution as a result of criminal coercion to prostitution as a career choice. Parts of the respondents' stories relate specifically to the different entry routes into this world, enabling us to dis-
} 
tinguish three types of prostitution. Each type differs in the degree to which taking up this route is a structurally constrained course of action, although the boundaries between these types cannot be traced precisely: classic prostitution, economic prostitution in the strict sense of the concept, and voluntary prostitution. Once more there is evidence of the diversity which characterises prostitution, a diversity that is also reflected in the different ways in which it is practised: full-time or part-time, recurrently or sporadically. Public intervention policies in Spain do not recognise this diversity and take for granted the stereotype of the prostitute as a victim of exploitation, a view informed by the abolitionist perspective. This can produce undesirable results, including a deterioration in the living and working conditions of women involved in prostitution.

Key words: coercion; structural constraint; sex work; abolitionism; employment rights; public policies; Spain.
Sumario
1. Introducción
5. Prostitución voluntaria
2. Entre la constricción criminal
6. Un debate esteril
y la opción vocacional
7. Las políticas de prostitución
3. Prostitución clásica
Referencias bibliográficas
4. Prostitución económica

\section{Introducción}

Desde hace algo más de una década, en España la prostitución femenina está cada vez más politizada. Varios acontecimientos ayudan a entender la creciente visibilidad del fenómeno, tanto en los medios de comunicación como en la agenda política:

1) El posible aumento del número de mujeres involucradas en el sector.

2) Su situación como inmigrantes irregulares, en algunos casos forzadas a incorporarse a la prostitución por las mismas redes delictivas que utilizan para entrar en el país.

3) La difusión del fenómeno más allá de su ubicación tradicional en el barrio chino de algunas ciudades y ciertos establecimientos de carretera.

4) Las protestas de los vecinos afectados exigiendo cuando menos que el comercio sexual no se desarrolle en su calle.

5) La correspondiente reacción de algunas administraciones locales y autonómicas, que se han visto obligadas a intervenir por vía indirecta en una cuestión que, en buena medida, no es de su competencia.

6) La reforma del Código Penal de 1995, a partir de la cual la prostitución propia ha dejado de ser ilegal, aunque sigue siendo socialmente ilícita (Fita, 2007) y un medio ilegítimo (no reconocido como ocupación) de acceso a rentas.

7) Finalmente, la reconversión de los discretos proxenetas tradicionales en empresarios de locales de alterne, formal y públicamente organizados para 
reclamar una nueva regulación del sector que permita sacarlo de la ambigüedad jurídica en que ahora se encuentra y ubicarlo en el marco de la legalidad.

A principios de siglo, a raíz de algunas iniciativas municipales, los medios de comunicación comenzaron a interpelar sobre el tema a los representantes de las fuerzas políticas parlamentarias. Creo no equivocarme al afirmar que, por razones de tipo pragmático, la mayoría se mostraron favorables a reconsiderar el «estatuto» actual de la prostitución — de matriz abolicionista - en sentido regulacionista. La minoría discordante tendía a repartirse por todo el arco parlamentario y defendía que lo único que debe hacerse con ella es erradicarla. Así, el debate incipiente se estableció más dentro de cada partido político que entre ellos. Pero cuando la controversia saltó a la sociedad civil, la correlación de fuerzas cambió de signo y el punto de vista erradicacionista ha acabado imponiéndose. Tanto es así que ésta es la posición oficial que finalmente asumió el Parlamento en 2007 en un informe plagado de contradicciones, cuya lectura sólo puede producir vergüenza ajena (Sanchis, 2008; Solana, 2008). Además, cierra el debate en falso, porque, más allá de su retórica abolicionista, en el fondo induce a dejar las cosas como están, no tanto en la alegalidad, como en una despenalización genérica que no satisface a nadie. Una situación equiparable a la británica, donde al final resulta que «es legal ser, pero no trabajar como prostituta» (Day, 1996: 75).

Al contrario de lo que suele ocurrir con los hechos controvertidos, en esta cuestión, la divisoria entre progresistas y conservadores no ayuda a entender los puntos de vista en litigio, pues, como en el caso de los partidos políticos, el debate se plantea sobre todo dentro de las propias filas. Ello está generando alianzas instrumentales entre actores sociales que suelen jugar en campo contrario y que pueden acabar lamentando no haber sido más cautos al elegir compañero de viaje (O'Connell, 2003). La fractura dentro del movimiento feminista ejemplifica muy bien lo que se viene diciendo (Gall, 2006: 2-3).

La posición erradicacionista mayoritaria es defendida por el feminismo radical. Según éste, la prostitución es una actividad perversa en sí misma, que atenta contra la dignidad no sólo de quien se prostituye, sino también de todas las mujeres. El cuerpo humano no puede ser objeto de transacción comercial, la mujer que se presta a ello es porque no tiene más remedio que hacerlo. La prostitución implica necesariamente violencia y explotación sexual, sólo existe porque las relaciones entre hombre y mujer están planteadas en términos de dominación y sumisión dentro de un sistema capitalista patriarcal que impide el establecimiento de relaciones igualitarias entre los seres humanos. Puesto que la prostitución es un mecanismo clave de sometimiento de todas las mujeres al hombre, con ella no cabe hacer otra cosa que acosarla por todos los medios hasta conseguir su erradicación definitiva. Reconocerle algún tipo de legitimidad obstaculiza gravemente este propósito. El modelo de referencia del feminismo radical es el neoprohibicionismo sueco, que se distingue del tradicional en que, al penalizar todo lo relacionado con la prostitución, incluye 
a la clientela masculina, pero excluye a la mujer que ofrece sus servicios en el mercado del sexo.

El feminismo liberal tiene como modelo de referencia el neorregulacionismo germano-holandés, que se distingue del tradicional en que reconoce la prostitución voluntaria de personas adultas como actividad laboral; una ocupación todo lo peculiar que se quiera, mediante la cual algunas personas (en particular mujeres) pueden ganarse la vida legítimamente. Desde esta perspectiva, la prostituta no vende su cuerpo, sino un servicio, como muchos otros trabajadores de la industria del sexo, donde se desempeñan actividades no fácilmente equiparables con la prostitución. El problema no sería tanto la actividad en sí misma como las condiciones que tienen que soportar muchas mujeres que se dedican a ella. La prostitución — se sostiene- puede ser también un trabajo bien remunerado e incluso satisfactorio y, por tanto, una vía de emancipación. Además, reconocerla como fuente legítima de ingresos contribuirá a desestigmatizarla y facilitará el asociacionismo y la sindicalización de las prostitutas, lo que sólo puede redundar en la mejora de sus condiciones de vida y de trabajo.

Si el debate sobre la prostitución se mantuviera estrictamente en el plano valorativo, nada tendría que decir la sociología al respecto, ya que, en principio, ésta se ocupa del ser, no del deber ser. Pero el hecho es que, en la defensa de las posiciones respectivas, se mezclan juicios de valor y de realidad, y tampoco respecto a estos últimos hay acuerdo. En general, la interpretación erradicacionista distorsiona la realidad prostitucional hasta niveles caricaturescos, mientras que los «laboristas» suelen ser más respetuosos con su complejidad. Paradójicamente, ésta es una de las razones que explican por qué el abolicionismo ha conseguido dominar el espacio público. Se trata de un movimiento

[...] bien organizado y centrado en unas cuantas estrategias, sobre todo la de simplificar lo complejo mediante argumentaciones, como la de que toda prostitución es violencia [...], que cualquier miembro de la sociedad puede captar rápido. [...] En cambio, el movimiento pro trabajo sexual ofrece un discurso [...] no reduccionista [...] que tiene necesariamente esas características, pues desea registrar una diversidad de realidades humanas. Además, dentro del mismo movimiento, hay distintos planteamientos sobre cómo se debería proceder, lo cual complica aún más la comprensión. (Agustín, 2008: 36-37)

En España, la controversia en torno a los hechos afecta básicamente a dos cuestiones: el número de mujeres involucradas en el sector y el carácter voluntario o forzoso de la prostitución adulta. Por lo que se refiere a la primera, los erradicacionistas más exagerados han llegado a aventurar la cifra de hasta 600.000 mujeres «prostituidas» (Brufao, 2008). Si esto fuera cierto, tendríamos más prostitutas que en cualquier otro país occidental, cuando menos en términos relativos. Por ejemplo, en Reino Unido, hay un amplio acuerdo en que debe haber unas 80.000 prostitutas (Kinnell, 2009: 214); en Francia, el Office Central pour la Répression de la Traite des Êtres Humains, a partir de fuentes policiales, estima que, en 2000 , había unas 15.000 prostitutas, 
un tercio de las cuales eran hombres (Portes, 2007: 71). Aproximaciones más respetuosas con el método científico, pero que no han podido evitar un nivel de imprecisión superior a lo deseable, sugieren que, en España, no habría muchas más de unas 100.000 prostitutas (Ingecon, 2007; Malgesini, sin fecha; Sanchis y Serra, 2009). La segunda cuestión es precisamente el objeto de este artículo.

Los erradicacionistas sostienen que la inmensa mayoría de las mujeres acceden a la prostitución forzadas, ya sea por mafias criminales o bien por una necesidad imperiosa que no les deja otra opción. Las muy pocas que se introducen voluntariamente en el sector son algo así como débiles mentales que deberían ser tratadas psicológicamente, porque nadie en su sano juicio puede elegir libremente esto. Tal diagnóstico falsea gravemente los hechos, obvia la complejidad del universo prostitucional y, en realidad, no es más que un trasunto del mito de la trata de blancas que tanto dio que hablar en Europa hace un siglo (Guy, 1992; Walkowitz, 1994; Doezema, 2000. Todos ellos citados en Agustín, 2009). Las entrevistas realizadas a veintitrés prostitutas en el marco de una investigación sobre la prostitución femenina en el País Valenciano (Serra, 2008), en particular los pasajes relativos a cómo entraron en el sector, arrojan luz sobre esta cuestión ${ }^{1}$.

\section{Entre la constricción criminal y la opción vocacional}

Desde que hay división social del trabajo, todas las sociedades distinguen entre actividades atractivas y repulsivas, que confieren prestigio a quien las realiza y que envilecen y sólo son desempeñadas por quien es obligado a hacerlas o no tiene alternativa. Dada la valoración social de que es objeto la prostitución, en principio cabe definirla como una actividad que nadie elegiría para ganarse la vida con ella. Ahora bien, si queremos entender los mecanismos concretos a través de los cuales se configura la oferta de prostitución, no podemos quedarnos aquí. Y para ir más allá, debemos contemplar todas las situaciones teóricamente posibles, definir un continuum delimitado por dos polos extremos que nos permita situar a las mujeres que ejercen la prostitución en algún

1. Las entrevistas se hicieron en otoño de 2007. Fueron grabadas y posteriormente transcritas. La mayoría de las mujeres fueron contactadas a través de organizaciones que trabajan en el sector, algunas directamente en la calle. Había catorce europeas (de las cuales siete españolas), seis latinoamericanas y tres africanas. Trece ejercían o habían ejercido en la calle, seis en clubes y cuatro en pisos. En el momento de la entrevista cinco habían abandonado la prostitución y una manifestó su deseo de hacerlo. Por edades, ocho tenían entre 23 y 29 años, otras ocho entre 30 y 39 y siete 40 o más. La más mayor tenía 46 años, siendo también la que más tiempo (26 años) llevaba ejerciendo; las dos que menos (dos meses) tenían 26 y 43 años. Cinco extranjeras estaban en situación documental irregular y otra tramitando su regularización. Catorce tenían hijos y seis manifestaron haber cursado más que estudios primarios. Las mujeres serán identificadas mediante un número precedido por la letra inicial del lugar donde se hicieron las entrevistas (Alicante, Castellón, Elche y Valencia). 
punto del espectro. Las dos posiciones extremas sólo pueden ser la prostitución criminalmente forzada y la vocacional.

Una parte minoritaria de la oferta de prostitución es criminalmente forzada: por lo general, se trata de extranjeras víctimas de trata o de ciertas modalidades de tráfico de personas. La desarticulación periódica, por parte de las fuerzas de seguridad, de redes mafiosas dedicadas a estas actividades es la prueba irrefutable de que el problema existe. Una de las mujeres entrevistadas manifestó tener noticia directa de la existencia de este tipo de tráfico, si bien no lo sufrió. Se trata de V2, nigeriana de veintitrés años que llegó a España en patera con un bebé de cinco meses, pasó dos años ejerciendo en la calle y, a través de Cáritas, consiguió regularizar su situación y dejar la prostitución. En su confuso pero dramático relato, hace referencia a la existencia de organizaciones que ofrecen traslado (en patera) y trabajo en España a cambio de contraer una deuda considerable que luego sólo puede ser satisfecha mediante la prostitución, en la que son introducidas por la misma red. Asimismo, V6 refiere el caso de una joven rumana de dieciséis años, cuya desaparición había sido denunciada por su madre, que fue liberada por la policía después de saber que estaba secuestrada en un burdel del barrio chino de Valencia.

Prescindiendo de estos casos, la prostitución se ejerce por la misma razón por la que se lleva a cabo cualquier actividad socialmente desvalorizada: por dinero. Por tanto, la necesidad de acceder a rentas tiene que estar presente en todos los itinerarios de acceso a la prostitución. Ahora bien, dinero se puede conseguir de muchas formas, incluyendo otras que tampoco gozan de prestigio social y que, sin embargo, son utilizadas por mucha gente para ganarse la vida. La alternativa más clara al alcance de la mayoría de las mujeres en prostitución es el servicio doméstico. En consecuencia, este factor sólo explica una parte de la cuestión, pero no por qué casi ninguna mujer opta por la prostitución, lo que nos obliga a considerar otros dos elementos. Primero, la dotación de capitales (en el sentido de Bourdieu) de que disponen las mujeres en prostitución; a menos dotación, menos alternativas. Puede suponerse que las que optan por la prostitución están escasamente dotadas, pero no que la mayoría de ellas lo están tan poco que no tienen ninguna alternativa. Segundo, la opción por la prostitución no implicaría tanto imposibilidad absoluta de obtener ingresos por otras vías, como imposibilidad de alcanzar el nivel de ingresos así obtenido. Además, tratándose de una actividad no sólo desvalorizada, sino también estigmatiza$\mathrm{da}$, cabe suponer que quien la elige ha de superar previamente la resistencia a hacerlo, que variará en función del grado en que tenga interiorizados los valores dominantes.

En resumen, la entrada en la prostitución puede analizarse combinando cuatro factores: necesidad de acceder a rentas, nivel de ingresos al alcance mediante una actividad alternativa, dotación de capitales y barreras culturales que se tienen que superar para dar el paso. La lectura de los relatos a partir de estas claves interpretativas permite clasificar a las mujeres entrevistadas en tres tipos básicos —ordenados en función de su distancia creciente respecto a la 
prostitución criminalmente forzada - que denominaremos prostitución clásica, económica y voluntaria ${ }^{2}$.

\section{Prostitución clásica}

Este tipo incluye a la mujer más desprovista de capitales, es decir, aquella que acumula todas las desventajas (económicas, sociales, culturales, familiares, psicológicas) y entra en la prostitución a una edad relativamente precoz tras una infancia difícil. Estos determinantes estructurales la llevan a una situación límite para la que no ve salida convencional. Está relativamente familiarizada con el mundo de la prostitución o alguien la pone en contacto con él; vence con más o menos dificultades la prevención inicial y comienza un itinerario del que confía escapar algún día. Pero su vida es un rosario de calamidades que se ven agravadas porque siempre toma la decisión equivocada, y ese día nunca acaba de llegar. Hemos escuchado algunos relatos dramáticos cuya verosimilitud es difícilmente cuestionable, en particular la de aquellas personas que han acabado felizmente con el abandono de la prostitución. Sin embargo, no puede descartarse que otros contengan cierta dosis de reelaboración autoconfortadora y justificadora a posteriori.

Este tipo tradicional integra, en la actualidad, dos elementos novedosos respecto a su versión «decimonónica»:

1) La condición de extranjera, equivalente funcional de la autóctona de extracción rural.

2) El consumo de drogas, que comenzó a ser significativo en la década de los ochenta. El perfil de varias entrevistadas se adapta bastante bien al tipo clásico. Además de V2, incluimos a nueve mujeres. El primer caso es el de una española de cuarenta y ocho años, en la prostitución

[...] desde los veinte años, cuando me separé de mi marido, sabes..., me casé muy joven, a los dieciséis, pero él empezó a pegarme... Me quedé en la calle con dos niñas y nada que comer. Además no quería volver a casa de mis padres [...] Es que nunca he tenido buena relación con mis padres, especialmente con mi madre. Soy adoptada [...] Un día, estaba en la plaza del mercado sentada en un banco con mis dos niñas y se acercó una mujer y me dijo: «¿Quieres trabajar?», y yo le dije que sí y me dijo: «Vente esta noche aquí», y desde entonces comencé a trabajar. (C5)

El segundo caso es el de una marroquí de cuarenta y cinco años ya regularizada. Viene a España en 1988 con su hermana mayor a ganarse la vida por medios convencionales. Se enamora, se empareja, se indispo-

2. Obviamente los tres tipos son prostitución voluntaria en el sentido de que en su origen no hay uso o amenaza de recurrir a la violencia psicofísica. Como se verá, si se califica de «voluntario" uno de ellos es para enfatizar que en éste, a diferencia de los otros dos, el peso de la constricción estructural es inexistente. 
ne con su hermana, tiene una hija, sufre maltrato, se separa y queda en desamparo:

Luego conocí al padre de mi hija, me junté con él. Luego tuve a mi niña, luego problemas... y luego ya me separé. A mi hermana le sentó muy mal... y cuando me separé no quiso ayudarme. Entonces había una persona siempre, que estaba encaprichado de mí cuando estaba con el padre de mi hija. Estaba encaprichado de mí y cuando me separé tenía problemas, me ofreció dinero a cambio de sexo para dar de comer a mi hija, y así seguí la ruta. (V1)

Otros dos casos, con sus variantes particulares, entran sin dificultad en este tipo. A2 es española, cuarenta y cinco años, sin estudios. Ha trabajado de aparadora en el calzado, lo que le ha provocado una enfermedad profesional, y de cocinera (siempre en precario). No se lleva bien con su madre. A los diecisiete años, su padre la echa del domicilio familiar. Se casa, tiene dos hijos, se separa, se junta con un alcohólico, tiene otro hijo, se vuelve a separar. El segundo compañero la introduce en el consumo de cocaína. Uno de los hijos es esquizofrénico. Asiste a una hermana durante su agonía, cae en depresión. Cargada de coca y porque quería más se introdujo en la prostitución hace menos de un año. Está intentando dejar la droga. Según cuenta, a la prostitución «no se llega por gusto, se llega porque pasa una cosa detrás de otra y te agobias y ya estám. A1 es también española, veintinueve años, sufre el divorcio de sus padres a los doce, vive hasta los diecisiete con su madre, cuando ésta mete a su nuevo compañero en casa. No lo soporta:

No quería volver a casa y empecé a alejarme. Entonces entré en las drogas y, a partir de ahí, en la prostitución [...] Fue una casualidad. Estaba con el síndrome de abstinencia y venía por aqui [por la zona de ejercicio] casualmente, y un coche me paró y me preguntó: «¿Cuánto cobras?». Yo le dije: «tanto», pero sin saber cuánto se cobraba, y así entré. (A1)

Posteriormente se desengancha de la droga y deja la prostitución, se casa, tiene dos hijos, se divorcia y vuelta a empezar. Ha trabajado en la limpieza en condiciones precarias. Actualmente intenta desengancharse a base de metadona, como su nuevo compañero, al que mantiene.

Podría decirse que E1, E2, E3 y C1 constituyen un subtipo dentro de la prostitución clásica. Se diferencian de los casos anteriores en que los determinantes estructurales pesan algo menos. Por una parte, su dotación de capitales es mayor; por otra, tienen menos resistencias culturales que vencer ante el sexo mercenario, lo ven como una posibilidad de ganar dinero rápido, fácil y abundante, y se meten en el negocio sin pensárselo dos veces. En este sentido, da la impresión de que la decisión de entrar en el oficio tuvo más que ver con las turbulencias psicológicas propias de la adolescencia que con los determinantes sociológicos. Algunas de ellas, luego, pretenderán salir sin saber cómo y lamentarán no haber medido mejor el alcance de su decisión. 
Me prostituía para llevar dinero a casa... Creo que tenía dieciséis años cuando empecé... Algunas vecinas que se dedicaban a ello... me decían que así ganaban dinero fácil... Pensé que era verdad, una forma muy fácil de ganar dinero [...] Empecé de prostituta porque quise y he seguido trabajando en ello porque quiero, nadie me ha obligado a meterme, fui yo la que, viendo a mis vecinas y oyendo que ganaban dinero, quise hacerlo yo también para tener dinero para hacer lo que yo quisiera y para ayudar en casa. (E1)

Estudié hasta la EGB y luego hice un curso de mecanografía. Intenté entrar en algún puesto [...], pero no [...], así que decidí ayudar a mi madre [calzado, trabajo a domicilio]. Intenté sacar dinero vendiendo droga [...] era muy fácil [...] Fue aquí donde conocí a una chica que se dedicaba a la prostitución y que también estaba traficando. Así que decidí probar porque a ella le iba muy bien. Por entonces, yo tenía diecinueve o veinte años [...] Y vi que se ganaba dinero y ya me quedé en esto, porque con lo que ganaba pasando [droga] y esto tenía suficiente, porque con lo de ayudar a mi madre en el calzado no daba para vivir. Cuando murió mi padre y tuve que encargarme de mi madre, pensé que ésta era la única forma de poder ganar dinero y cuidarla. No lo podría haber hecho con cualquier otro trabajo. (E3)

Estos dos casos tienen en común que proceden de un medio social desfavorecido. En el caso siguiente, las variables clave son la droga y la familia:

Cuando estaba acabando el instituto, me metí en problemas de droga. Cuando mis padres se enteraron, me echaron de casa y renegaron de mí [...] Empecé a trabajar en la prostitución porque el chico con el que vivía después de que mis padres me echaran de casa me decía que tenía que sacar dinero para pagar las drogas. Fue él el que me introdujo, pero no lo hice por él, sino porque necesitábamos ese dinero. Los dos consumíamos y gastábamos mucho dinero en las drogas. De alguna forma había que pagarlo, pero él no me obligó. No me puso una pistola en la cabeza, aunque sí que me sentí un poco presionada para ganar dinero y, según él, era la forma más fácil. (E2)

Pero es en C1 donde parece destacar con más fuerza como factor determinante el haber tomado a la ligera una decisión trascendental para la vida de una persona. Por ello hemos optado por incluirla en este tipo antes que en el siguiente, ya que la lógica instrumental que manifiesta en su discurso sugiere que es un ejemplo claro de lo que hemos llamado prostitución económica:

Yo te digo que empecé por sinvergüenzura. Comencé en mi país de origen porque trabajaba para Coca-Cola... Conocí a una amiga... y veía que ella no trabajaba pero que siempre cargaba dinero encima... y yo me preguntaba "¿qué haces?», y ella me dijo: "yo es que tengo unos amigos y me pagan por salir con ellos, ¿quieres probarlo?». Y el primer día que salí [...] me gané bastante dinero [...] y empecé a sacar cuentas [...] y dije [...] yo me pongo como prostituta. Gano más, la paso bien, me llevan al restaurante, me llevan a la discoteca y aparte me pagan. ¡Que yo para ese dinero me tengo que estar un mes currando! [...] Eso me llevó a ser prostituta. Realmente, la codicia. (C1) 
Otro elemento que comparten estas cuatro mujeres es la vehemencia con que reclaman haber tomado libremente la decisión de entrar en el oficio. Sin embargo, estas manifestaciones deben ser interpretadas con cautela, pues pueden estar sesgadas por el deseo de presentar una imagen de sí mismas que quizás no se corresponde con la realidad.

Por último, el caso de V3 roza el límite de la prostitución clásica y nos introduce en el tipo siguiente. Se trata de una subsahariana de cuarenta años, con estudios (por eso decimos que está en el límite) y un año de ejercicio. Viene a España en busca de asistencia especializada para su hijo enfermo del corazón, se gana la vida como puede, siempre en precario, y acaba en la prostitución callejera ante la falta de alternativas satisfactorias, es decir, adecuadamente remuneradas.

\section{Prostitución económica}

Ahora tenemos una mujer de biografía convencional, no mal dotada de capitales, que, en un momento dado (por circunstancias estructurales o personales), se ve afectada por una grave carencia de recursos económicos, valora de modo realista las alternativas a su alcance y opta por la prostitución. Es una mujer madura, psicológicamente fuerte, que jamás había imaginado que podría acabar así, pero que controla la situación, no se deja estigmatizar por ella y confía en recuperar la normalidad cuando cambien las circunstancias. Vence las resistencias iniciales a base de racionalidad económica (la prostitución es un trabajo como muchos otros, con sus ventajas y sus inconvenientes) y no hace de su integridad sexual una cuestión de honor. En la vida hay otras cosas más importantes, como pagar el alquiler a fin de mes o sacar adelante a los hijos. E4, C2, C3, A3, A5, A6, A7 y V6 se ajustan bastante bien a este tipo.

Me quedé sin trabajo en el calzado cuando mi fábrica cerró, así que me metí en esto por la falta de dinero, pero no fue una obligación, podría haber elegido otra cosa, pero decidí elegir ésta antes que fregar escaleras. Porque gano más dinero, el horario lo pongo yo y cuando no quiero, no trabajo. (E4)

C3 es argentina, cuarenta y tres años, fisioterapeuta, tenía un centro de masajes («y ahí me pedían aparatitos y acabé con látigos»). Se dedica al sado. Empieza en su país cuando se le juntan la crisis económica y el divorcio y ha acabado en España, desde donde envía dinero a sus dos hijos, que tienen previsto venir a reunirse con ella.

¿Qué es para mí prostituirme? No sabría contestarte. Es una necesidad extrema, no sé si uno elige [...] Como no tienes otra alternativa, lo elegís. Para mí fue así, tenía treinta y ocho años y no me quedaba otra alternativa [...] Esto $[\ldots]$ con el tiempo es una profesión, con cuarenta y tres años es lo más difícil que he tenido que hacer. Hasta hoy en día me resulta difícil hacer un servicio. (C3) 
A7 es venezolana, veinticinco años, viene a España a los veinte a trabajar en la prostitución por un motivo muy concreto. Luego la cosa se complica y aparece un elemento característico de la prostitución clásica:

Yo estudiaba, trabajaba, estaba muy bien [...] pero mi mamá enfermó de cáncer y por el seguro tardaba mucho tiempo. Por la clínica me costaba mucho dinero [...] Una amiga me comentó cómo se ganaba, cómo eran las circunstancias [...] Una amiga que estaba aquí trabajaba para una persona que es la que me pagó el billete, la persona a la que le cancelé la deuda, porque no fue gratis [...] Sabía a lo que venía [...] Mi mamá tenía cáncer y tenía que operarla. Ahora, gracias a Dios, está curada [...] Yo vine aquí a hacer dinero y cuanto antes mejor, antes me vuelvo. Lo que pasó es que me enamoré de una persona, me salí, tuve un niño y volví. (A7)

Quizás sea V7 quien mejor representa la prostitución económica. Portuguesa, treinta y ocho años, situación familiar convencional (pareja de hecho desde hace veinte años, tres hijos). Vienen a España no huyendo de la miseria, sino en busca de nuevas oportunidades ( $\mathrm{Si}$ funciona, funciona, y si no funciona, cogemos la maleta y nos volvemos atrás, como hace todo el mundo»). Al principio, todo va bien, luego el marido pierde el empleo, busca sin éxito, ella recurre al servicio doméstico, la situación se agrava, una vecina le explica que hay otras formas de ganar dinero... La primera vez que se pone en la calle, con veintisiete años, lo pasa muy mal. Una veterana le echa una mano, la tranquiliza y le explica los rudimentos del oficio. Pone al corriente de la situación al marido, quien no tiene más remedio que asumirla («estuvo dos días llorando»), y así hasta hoy. En la actualidad, once años después de aquella primera vez, las cosas van mejor. El marido trabaja de pintor, ella tiene unos cuantos clientes de confianza y ejerce unos ocho días al mes. Así obtiene entre quinientos y seiscientos euros y redondea el presupuesto familiar. Más no le hace falta, porque tiene las cosas muy claras: «Mi obsesión es pagar el alquiler y que cuando mis hijos se sienten a la mesa tengan siempre algo que comer, eso para mí es lo más importante». «¿Pero es un trabajo digno, como cualquier otro?», le preguntamos. "Para mí sí, un trabajo como cualquier otro. [...] Digno, claro, el trabajo es digno", responde. "A mí nadie me ha obligado. Yo he decidido. He visto una situación de mi vida en la que yo necesitaba de dinero. Robar, no sirvo para robar. Para engañar, tampoco sirvo para engañar. Para esto tampoco servía, pero...». No obstante, ya va siendo hora de dejarlo, porque su hijo mayor está más o menos al corriente, pero preferiría que su hija de ocho años no acabara enterándose. En realidad, lo que quiere es una nómina, porque es la única manera de poder comprarse un piso, pero entre fregar platos sin contrato y ejercer la prostitución...

\section{Prostitución voluntaria}

En un mundo que tiende a fomentar el consumo compulsivo, cada vez es más difícil distinguir entre necesidades y deseos. Aun reconociendo la imposibilidad 
de fijar el punto exacto donde acaban unas y empiezan otros, no se puede negar que mucha gente los confunde. El objetivo de conseguir más dinero de la forma más rápida posible y a través de no importa qué medio ocupa una posición relevante en la escala de valores. De acuerdo con ello, puede afirmarse que hay mujeres que se dedican voluntariamente a la prostitución para satisfacer deseos consumistas más que necesidades y en respuesta a motivaciones muy alejadas de las que generan el tipo clásico; mujeres que, sin estar abrumadas por los determinantes estructurales, primero calculan metódicamente los costes y los beneficios que puede acarrearles la prostitución y después optan por ella.

Ninguna de nuestras entrevistadas trabaja en la prostitución de alto standing, pero ese mundo existe, y en él están involucradas mujeres (también españolas) situadas en las antípodas de la marginación socioeconómica que podrían prescindir sin ningún problema de esta actividad, pero que la practican al objeto de conseguir ingresos elevados (Ballester et al., 2003: 127-128, 130). Asimismo, los testimonios que algunas mujeres han dejado escritos sobre su propia experiencia muestran que las hay confortablemente instaladas en la prostitución. Cuatro de las entrevistadas pueden ser consideradas voluntarias, si bien comparten algunos rasgos con las mujeres de los otros tipos. Se trata de A4, V4 y V5 (dos mujeres).

A4 está en el límite entre la prostitución económica y la voluntaria. Tiene treinta y dos años, hace dos y medio vino directamente desde Suramérica a iniciarse en el oficio en el club donde trabaja y (según nos dice) vive cómodamente. Aunque procede de una familia muy pobre, su situación no era desesperada. Ejerce su nueva ocupación, en la que se introdujo sin problemas, con profesionalidad. Controla estrictamente sus gastos, ni siquiera prueba el alcohol o el tabaco, envía dinero a la familia de origen, a la propia y ahorra. $\mathrm{Su}$ ilusión es montar una gasolinera en su país. En un mes, regresa a casa y, si todo va bien, cierra definitivamente esta etapa de su vida, aunque no descarta tener que volver algún día.

V4 tiene veintitrés años y procede de una familia absolutamente convencional, incluso acomodada. Un buen día, hace tres años, decide abandonar los estudios universitarios e irse a Londres.

Quería dejar los estudios y quería hacerme un viaje a Londres [...] y necesitaba el dinero rápido, porque era un intervalo de mes y medio para el billete de avión. Fue así, me planteé trabajar de cualquier otra cosa, pero entre que te pones a buscar, pasar la entrevista, que te llaman [...] Y como siempre me había interesado este tema, había leído libros y entrevistas, ya sabía cómo moverme y por dónde moverme [...] Era dinero fácil y rápido, que es lo que quiero [...] Era mi sueño en ese momento, era lo que yo quería hacer [viaje a Londres] y no puedo permitírmelo, así que, aunque tengas que hacer esto, pues lo haces, ¿no? (V4)

Una mujer decidida que perdió la virginidad con su primer cliente. La prostitución ahora no le parece un trabajo fácil, pero le da dinero. A ella no le 
gusta («Sólo pones tu cuerpo y ya está») y le impide (psicológicamente) tener relaciones sexuales convencionales. En la actualidad, la compagina con otras actividades y espera dejarla cuando tenga bastante dinero para poder embarcarse en proyectos más estimulantes en los que su talento no se eche a perder.

El relato de V4 debe ser analizado con atención por diversas razones. Para comenzar, porque ofrece una visión de este mundo absolutamente alejada de su estereotipo, que descansa sobre todo en la prostitución callejera (la modalidad más sórdida pero también la menos practicada) y pone demasiado énfasis en la coerción criminal. Ella tenía claro desde el principio que, en la calle, no le interesaba trabajar, y sabía (por lecturas como el Yo puta, de Isabel Pisano, porque no tenía ninguna relación con la prostitución) que, a través de ciertos anuncios de prensa, podría encontrar trabajo en el sector. Así lo hizo, y una vez dentro, a lo largo de tres años, ha conseguido tener su propia cartera de clientes, con los que contacta fuera de los pisos y con ello se ahorra el 50-60\% de comisión. Ha trabajado en todo tipo de apartamentos, algunos muy cutres (en los que suele haber más extranjeras), otros higiénicos y muy bien acondicionados en los que predominan las españolas. Ninguna de las mujeres que ha conocido durante este tiempo ha entrado o está en la prostitución forzada por terceras personas. Por una parte, dice que «hay muchas mujeres que se meten en esto por necesidad»; por otra, no lo acaba de ver claro, porque «yo siempre lo diré, siempre, que hay trabajos [...] que si no quieres dedicarte a esto no lo tienes por qué hacer». En cuanto a esos testimonios que salen por la tele sobre mujeres abandonadas por sus maridos o que se quedan viudas, "Es que no, no me creo esto. Hay muchos trabajos que se pueden adaptar a ti». Si se meten en la prostitución, es porque proporciona «dinero rápido y fácil». Además, otras lo hacen para pagarse sus caprichos. En 2004, en el primer piso en que trabajó, conoció a:

[...] gente encantadora, que te hablaba de sus problemas, gente española, ¿sabes?, simplemente que se dedicaban a eso porque querían [...] tenían títulos, esteticista, de no sé qué, pero no les apetecía..., les apetecía sacar dinero para gastarse en el Corte Inglés [...] Casi todas tienen marido e hijos mayores, sí... A lo mejor te decían: «Este mes me toca trabajar más, porque le quiero comprar el ordenador al chiquillo».

Otro elemento a destacar en relación con V4 es la forma en que fue localizada. Acceder a una prostituta grabadora en mano y conseguir que hable sin reservas no es tarea fácil, requiere la estrategia y la paciencia del antropólogo, tiempo. Nosotros no disponíamos de él y utilizamos la vía más transitada: la mediación de organizaciones de ayuda a las prostitutas, por lo general orientadas a conseguir que dejen el sector. Esto puede provocar que la entrevistada cuente lo que considera que se espera de ella y proceder a una reelaboración de su experiencia a base de incorporar elementos de lo que hemos llamado el tipo clásico, lo que complica el análisis de los discursos. V4 fue contactada por una de esas casualidades que suelen darse en todo trabajo de campo: era amiga 
de una amiga de una de las investigadoras, se prestó con interés a la entrevista y habló con absoluta libertad.

V5 son, en realidad, dos rumanas de veintitrés años que fueron entrevistadas conjuntamente en el club donde trabajan en un municipio del área metropolitana de Valencia. Un establecimiento muy bien organizado y conocido que ha sido pionero en la llamada prostitución de plaza. Tienen muy claro lo que están haciendo y para qué: una actividad temporal que no es fácil ni agradable, pero que les permite ganar mucho dinero en poco tiempo. C. ejerce desde hace año y medio. Su primer trabajo en España fue de camarera, pero pronto se dio cuenta de que la prostitución era mucho más rentable. Sus proyectos para cuando vuelva a Rumanía están bastante bien definidos. D. lleva un año escaso en el oficio, vino directamente a ejercerlo y todavía no tiene muy claro qué hará cuando lo deje. ¿Por qué las incluimos en la prostitución voluntaria y no en la económica? Porque no parecen estar particularmente desprovistas de capitales y el detonante de su decisión no ha sido un acontecimiento especialmente dramático, fortuito, inesperado, sino más bien la falta de paciencia para abrirse camino en la vida por medios convencionales. Expresado en términos mertonianos, estamos ante casos muy claros de desviación, no respecto a fines socialmente legítimos (enriquecerse), sino respecto a los medios utilizados para alcanzarlos.

Las veintitrés mujeres entrevistadas permiten hacerse una idea de la complejidad del universo prostitucional, pero no la agotan. Entre otras razones, porque cabe la posibilidad de que la prostitución vocacional sea algo más que un mero recurso metodológico. La historia que nos cuenta el cineasta Francesc Betriu en su imprescindible documental Mónica del Raval (2008) es real, y parece que sólo permite dos interpretaciones:

1) Mónica es una persona plenamente adulta que disfruta con lo que hace.

2) Arrastra, desde su adolescencia, algún tipo de tara psicológica que nubla su entendimiento.

Aceptando que, en nuestra cultura, está profundamente interiorizada la idea de que el intercambio sexual sólo puede ser gratificante en un contexto relacional donde el acuerdo mercenario no tiene cabida, la tentación de optar por la segunda es fuerte. Sin embargo, antes de hacerlo, el sociólogo debe reconocer que esta cuestión desborda los límites de su disciplina y recordar que tiene la obligación metodológica de evitar todo complejo de superioridad al observar la realidad que pretende comprender.

No sin dificultad, nuestras mujeres han sido clasificadas en tres categorías que representarían otros tantos itinerarios de entrada en el oficio ordenados, como ya se ha dicho, en función de su distancia creciente respecto de la prostitución criminalmente forzada: clásica (diez casos), económica (nueve) y voluntaria (cuatro). A su vez, dentro de la prostitución clásica cabe distinguir tres subtipos. El primero, probablemente en declive, está constituido por mujeres autóctonas procedentes de la marginación social. En el segundo 
caso, la variable clave es la drogodependencia, que al parecer ya no tiene la importancia que llegó a alcanzar durante los años ochenta y noventa. Por otra parte, el hecho de que no pocas mujeres se iniciaran en la prostitución a una edad relativamente precoz sugiere que en algunos casos la falta de madurez psicológica también puede desempeñar su papel. El elemento diferenciador del tercer subtipo (emergente) es la condición inmigrante, que en una década escasa ha transformado radicalmente el mundo de la prostitución. A diferencia de las primeras, estas mujeres no proceden necesariamente de ambientes marginales, y probablemente están menos desprovistas de capitales y gozan de mayor capacidad de decisión, pues la mayoría de ellas saben a lo que vienen (Meneses, 2003: 14).

\section{Un debate estéril}

Imaginemos por un momento un debate sobre los problemas de la minería, el servicio doméstico o la emigración económica y la manera de hacerles frente. ¿Tiene sentido centrarlo en la voluntariedad con que se llevan a cabo estas actividades? En perspectiva sociológica, no demasiado, porque nadie discute que la acción social es siempre consecuencia de una decisión tomada libremente por el sujeto en un marco de constricciones estructurales. Lo que distingue la prostitución de todas esas actividades es su carácter estigmatizador y que se le niega legitimidad como vía de acceso a rentas. Pero ello no significa que la mayoría de quienes la practican no puedan hacer otra cosa. «Es evidente que, como en el caso de las restantes labores y trabajos, no se trata de una opción libre, dado que se realiza para satisfacer necesidades económicas, pero tampoco suele ser una opción sobredeterminada externamente, porque normalmente la mujer tiene otras opciones alternativas» (Juliano, 2003: 191). En una sociedad atravesada por desigualdades de raza, etnia, género o clase, pocos individuos pueden elegir libremente, pero esto no quiere decir que algunas mujeres no puedan tomar racionalmente la decisión de trabajar en la prostitución (Chapkis, 1997: 67). Convertir la constricción estructural en determinación social y equiparar ésta con la coerción criminal es una operación intelectualmente espuria que distorsiona la realidad prostitucional y sólo puede inspirar políticas contraproducentes para hacer frente a sus problemas.

Los relatos de las veintitrés mujeres aquí reflejados son sólo un indicio más de que leer la prostitución en clave de esclavitud y explotación sexual es confundir la parte con el todo:

Lo que nos parece importante destacar desde el punto de vista sociológico es que esta figura de la víctima de la trata no mantiene más que relaciones distantes con la realidad de la prostitución de las mujeres jóvenes extranjeras. En primer lugar en términos cuantitativos: las cifras que se aducen para apoyar las denuncias de trata son absolutamente alucinantes [unas 500.000 mujeres en la UE-15]. Pero es una vez más la representación de quienes son las «víctimas de la trata» lo que plantea problemas. [...] no siempre son víctimas pasivas, sino 
también actoras à part entière de la trata, que persiguen proyectos migratorios propios. (Mathieu, 2007: 35-36)

En Italia, a partir de las apreciaciones de unos ciento cincuenta informantes clave (trabajadores sociales y agentes de las fuerzas del orden), se estima que un 7-8\% de la prostitución callejera adulta está sometida a coerción criminal (violencia psicofísica). El resto, sin precisar en qué proporción, se distribuye entre prostitución "voluntaria» e «instrumental», esto es, mujeres que se "autoimponen» el ejercicio de la prostitución para acceder a rentas (Carchedi y Tola, 2008: 99-102). Las cincuenta y cinco mujeres entrevistadas en Birmingham manifestaron haberse incorporado al sector por su propia voluntad. Todas eran ciudadanas británicas, y cuarenta y cinco, europeas blancas. Quince habían sufrido abusos sexuales o físicos durante su infancia y relaciones familiares problemáticas. De las veintiocho que estaban casadas o emparejadas, trece no le habían dicho al compañero que se dedicaban a la prostitución. De las cuarenta y una que tenían hijos, veintiuna se definieron como lone parents y declararon haber entrado en la prostitución para mantenerlos. De las once que siguieron estudiando tras la enseñanza obligatoria, cinco acabaron professional nursing training y otras dos, un primer ciclo universitario. En el momento de la investigación, tres estaban haciendo estudios universitarios (Sanders, 2008). En un estudio etnográfico sobre la inmigración dominicana y marroquí en Madrid, se han detectado dos vías de acceso a la prostitución: "Por un lado, algunas mujeres que han trabajado primero en el servicio doméstico deciden buscar un trabajo sexual, casi siempre como una estrategia de aumentar los ingresos y para poder tener una vida propia a la que no tienen acceso cuando trabajan como internas en una casa. Por otro lado, existen redes de prostitución tejidas desde los países de origen que no dejan muchas alternativas a las mujeres que viajan al amparo de éstas» (Gregorio y Ramírez, 2000: 271). Preguntadas en Galicia ciento dos mujeres sobre las razones por las que acabaron en la prostitución, el 14,7\% respondieron que las obligaron, el 15,7\%, que eligieron libremente, y el 69,6\%, que no veían otra alternativa (QUESTDATA, 2004: 257). Más en general, las investigaciones llevadas a cabo en distintas ciudades y regiones españolas permiten formular, entre otras, la conclusión siguiente: «Sus autoras/es no niegan la existencia de casos de tráfico y trata de mujeres con fines de explotación sexual, incluso los constatan. Pero más allá de ellos, revelan la existencia de una multiplicidad de organizaciones, procedimientos y mecanismos, tanto de emigración para emplearse en la prostitución como de entrada a ésta, irreductibles al esquema de organizaciones mafiosas de tráfico y trata de mujeres» (Solana, 2007: 47).

No es necesario seguir argumentando en defensa de lo evidente: la mayoría de las prostitutas tienen muy poco que ver con la víctima pasiva de la coerción criminal y la sobredeterminación estructural; el ejercicio de la prostitución se caracteriza por su acentuada diversidad, lo que, a su vez, muestra la debilidad del estereotipo. Son muy pocas (y pocos) las que se dedican profesionalmente, a tiempo completo y durante toda su vida adulta a esto. La prostitución es 
también una actividad temporal que se abandona una vez conseguidos ciertos objetivos económicos, que puede formar parte de un ciclo anual de trabajo y que se combina con otras actividades generadoras de rentas (Kempadoo, 1998: 3-4). Aplicar energía intelectual a discutir una cuestión como ésta sólo tiene sentido en el contexto español por dos razones. Primera, porque la posición de quienes pretenden introducir racionalidad en una polémica emocionalmente muy cargada todavía requiere aliados. Segunda, porque — como ya se ha apuntado a lo largo de este artículo- las políticas de prostitución inspiradas en el punto de vista abolicionista sólo pueden contribuir a empeorar las condiciones de vida y de trabajo de la mayoría de las prostitutas. Para algunos estudiosos, se trata además de un debate estéril, pues el sexo venal no puede «ser considerado a priori ni como un "oficio" [como cualquier otro] ni como una "esclavitud". Estos debates no han hecho avanzar ni un ápice la reflexión sobre la prostitución, sino que sobre todo han impedido a feministas [antiprostitución] y defensores de los prostitué.e.s, agotándolos y enfrentándolos en vanas polémicas, unirse eficazmente en una oposición resuelta a esta política [la de Sarkozy] de insécurisation de los sectores más dominados y frágiles de la sociedad francesa» (Mathieu, 2007: 40).

Más aún, quienes lucharon en su momento por introducir la distinción entre prostitución voluntaria y forzada - los mismos que reivindican la denominación de sex workers para escapar del estigma asociado a la de puta o prostituta - , ahora reclaman la necesidad de obviarla, porque se está convirtiendo en una nueva justificación para negar los derechos humanos de las prostitutas en cuanto tales (Doezema, 1998). Una vez más, en España estamos de ida cuando en otros sitios ya están de vuelta. Doezema no niega que haya trabajadores del sexo en condiciones de semiesclavitud, ni que sea posible elegir racionalmente la prostitución como actividad remunerada. Lo que sostiene es que «la dicotomía entre voluntaria y forzada es un marco teórico inadecuado para analizar la experiencia de los trabajadores del sexo».

La distinción entre prostitución libre y forzada fue defendida por el movimiento pro derechos de las prostitutas liderado por ellas mismas en respuesta al abolicionismo, argumentando que la lucha contra la prostitución y la trata no podía hacerse a costa del derecho a la autodeterminación de las personas adultas voluntariamente involucradas en el sector. Así, frente al discurso abolicionista dominante a nivel internacional durante un siglo, la reivindicación del trabajo sexual como ocupación legítima ha ido ganando reconocimiento, y desde mediados de los años ochenta, en Naciones Unidas (aunque no de manera unánime), se comienza a sustituir la condena genérica de la prostitución por la de la forzada, al tiempo que se habla menos de coerción criminal y más de problemas asociados con la pobreza en diversas partes del mundo.

Ahora bien — siempre según Doezema—, esto no puede interpretarse como un paso adelante en el reconocimiento de los derechos de los trabajadores del sexo. Que la comunidad internacional esté de acuerdo en condenar sólo la prostitución forzada no significa que lo esté en cuanto a qué hacer con la prostitución voluntaria, ni siquiera sobre si en realidad existe tal cosa. De 
hecho, si hay acuerdo sobre la prostitución forzada es porque no lo hay sobre la voluntaria. Lo que tenemos es una especie de compromiso según el cual quienes desean erradicar toda forma de prostitución pueden sentirse satisfechos de que, al menos así, los peores abusos están siendo atacados, mientras que quienes defienden el derecho a decidir de los trabajadores del sexo se conforman con que éste no resulte amenazado.

Los trabajadores del sexo y los movimientos pro derechos de las prostitutas tradicionalmente se han enfrentado al abolicionismo, pero ahora son cada vez más críticos con los activistas de los derechos humanos y antitráfico. Porque no los tienen en cuenta cuando planifican sus campañas. Porque utilizan el mismo lenguaje emotivo que los abolicionistas, con lo cual perpetúan el estereotipo de víctimas pasivas y explotadas. Porque, si bien distinguen entre un tipo de prostitución y otro, en realidad, dedican todos sus esfuerzos a luchar contra la prostitución forzada ignorando sus derechos. Pero lo más preocupante, según ellos, es que la dicotomía entre voluntaria y forzada crea falsas divisiones entre los trabajadores del sexo, al reeditar en lenguaje aggiornato la vieja distinción entre puta y madonna. Por una parte, tendríamos a la voluntaria, occidental, emancipada, capaz de tomar decisiones autónomas sobre si vender o no sexo. Por otra, a la forzada, habitante de un país en desarrollo, pasiva, incapaz de decidir a causa de la pobreza extrema, ingenua y fácil presa de los traficantes. Pero sobre todo tendríamos voluntarias culpables de haber elegido el mal camino, cuyos derechos no hay que defender, pues en el fondo se merecen lo que les pueda pasar, y forzadas inocentes cuyo derecho fundamental es el de ser rescatadas de su condición. Porque una cosa es salvar víctimas inocentes de la prostitución forzada, aunque sólo sea por la necesidad, y otra defender que las prostitutas en cuanto tales también tienen derechos aunque no quieran dejar de serlo. Dicho brevemente, lo que comenzó siendo una carga de profundidad contra el estereotipo de la prostituta como víctima, ha sido cooptado y reconvertido en una excusa no tanto para negar los derechos de las prostitutas, pero sí para seguir ignorándolos.

\section{Las políticas de prostitución}

Aunque discutir a fondo las políticas de prostitución requeriría un artículo aparte, quiero acabar éste esbozando algunas ideas que quizá tengan utilidad en el contexto español cuando el debate, oficialmente cerrado (en falso), vuelva a pasar a primer plano. Huelga decir, pero en este caso hay que hacerlo, que condición necesaria de toda política de intervención es un diagnóstico previo del problema que defina sus características básicas y las causas que lo generan. Tal diagnóstico exige mantener separados el plano de los hechos y el de las valoraciones, no confundir el ser con el deber ser. Las políticas son, por definición, valorativas, pues pretenden orientar la realidad tal como es hacia una situación más acorde con los valores en que se inspiran. Pero fundamentar opciones ideológicas legítimas en juicios de realidad tergiversantes sólo puede llevar a callejones sin salida. Digámoslo claramente, las políticas de prostitución 
que se están llevando a cabo en España derivadas del diagnóstico de los abolicionistas van a producir el mismo resultado que las que intentan acabar con la inmigración irregular blindando fronteras y desmantelando redes criminales de tráfico de personas. La diversidad que caracteriza el universo prostitucional exige políticas diferenciadas, moduladas en función del tipo de prostitución de que se trate. En todo caso, el objetivo de erradicar la prostitución no debería pagar el peaje de complicar más aún la vida de las mujeres que se la ganan con ella.

La intensa colonización del sector por inmigrantes que se aprecia desde hace más de una década añade complejidad al tema. La represión del tráfico de personas con fines de explotación sexual no puede ser el caballo de Troya de procedimientos de control de la inmigración irregular poco compatibles con la sensibilidad democrática y la retórica de los derechos humanos. El discurso abolicionista del rescate y la reinserción muestra todas sus contradicciones y limitaciones ante las inmigrantes en prostitución, pues muchas de ellas de lo único que quieren escapar es de su condición de sin papeles, y como casi ninguna ha sido secuestrada por una red mafiosa, sólo se van a encontrar con la expulsión (Colectivo Ioé y Agustín, 2001: 698). Las políticas de prostitución tienen que diseñarse en estrecha coordinación con la de regulación de los flujos migratorios.

Todas las políticas tienen efectos no deseados. Desde las neoprohibicionistas inspiradas en el abolicionismo, aunque sus partidarios no lo reconozcan, hasta las neorregulacionistas "laboristas» (Mckeganey y Barnard, 1997: 101103), como reconocen muchos de los que las propugnan, que no necesariamente simpatizan con el oficio. También los tiene (lo único que nadie discute) la política de dejar las cosas como están, que es lo que de hecho está propiciando la retórica abolicionista.

Desde finales del siglo xIx, las políticas de prostitución han atacado problemas como la preservación de la moral y las buenas costumbres, la seguridad ciudadana o la higiene y el orden públicos. Desde mediados del siglo xx, la prostitución ha pasado a ser también otro escenario donde librar la guerra de sexos contra la sociedad patriarcal y por la dignidad de todas las mujeres. Aquí y ahora, no estaría de más plantearse como objetivo prioritario el de mejorar la situación de las mujeres que practican la prostitución. De todas ellas.

En primer lugar, de la minoría sometida a coerción criminal; para esto y poco más sirven algunas de las recomendaciones formuladas en el informe de la Ponencia sobre la prostitución de la Comisión Mixta de los Derechos de la Mujer. En segundo lugar, de las que entraron abrumadas por la constricción estructural y quieren dedicarse a otra cosa, sin perder de vista que, si la alternativa es el servicio doméstico, siempre habrá quien prefiera aguantar las impertinencias del señorito en la cama antes que en la mesa. Al final, es una cuestión de coste de oportunidad. Por último, de las que utilizan la prostitución (a tiempo completo o parcial, recurrente $\mathrm{u}$ ocasionalmente) como fuente válida de ingresos y consideran que todavía no ha llegado el momento de dejarla. Estas mujeres no necesitan ser rescatadas y también tienen derecho a vivir y a trabajar en paz. Su problema no es tanto la prostitución como las condiciones 
que, a menudo, tienen que soportar para ejercerla, así como el estigma que la acompaña. Luchar contra ese estigma antes que contra toda forma de prostitución tampoco es mal objetivo.

Es sobre todo la situación de este tercer colectivo lo que obliga a reflexionar sobre la cuestión del reconocimiento de derechos laborales, en absoluto sencilla. Primero, por las posibles consecuencias perversas. Las de no reconocerlos son evidentes, pero ¿̨habría que hacerlo sólo con las autóctonas para evitar el efecto llamada, como se hace en algunos países neorregulacionistas? Segundo, por la composición heterogénea del colectivo. Distingamos al menos entre las profesionales y las oportunistas. Dentro del primer grupo, están las líderes "laboristas», mujeres emancipadas que han conseguido sacudirse el estigma y merecen ser escuchadas, sin que la histeria abolicionista lo impida. Dentro del segundo, muchas de las que no habría que preocuparse demasiado, porque se cuidan solas. A éstas los derechos de las prostitutas no les quitan el sueño; sólo quieren pasar desapercibidas, que la sociedad mire hacia otro lado y no se inmiscuya en sus asuntos.

Las laboristas tienen derecho a reclamar la normalización de la prostitución como actividad laboral y, a la luz de lo que ha ocurrido con otras minorías tradicionalmente excluidas, es posible que lo consigan. La sociedad, por su parte, también lo tiene a seguir negándole legitimidad. ¿Qué hacer? Si aceptamos la necesidad de conjugar la ética de los principios con la de la responsabilidad, podrían ensayarse soluciones de compromiso, intentar combinar el objetivo a largo plazo de erradicar la prostitución con la finalidad inaplazable de mejorar las condiciones de vida y de trabajo de las prostitutas. Para orientar el celo de las fuerzas del orden más hacia los clientes poco recomendables y menos hacia quienes se ganan la vida con ellos, no hacen falta innovaciones normativas. Apelando al sentido común y al pragmatismo, puede concebirse una vía intermedia entre el sí y el no formal al reconocimiento de derechos laborales: asumir que es ilusorio pretender regular de manera inequívoca éste y otros ámbitos de la vida social particularmente delicados y reconocer de hecho, por la puerta de atrás, el acceso a derechos. El resultado no es evidente, pero si se sacara la reflexión sobre la prostitución del ámbito de la sociología de la marginación, del delito o de la conducta desviada y se ubicara en el de la sociología del trabajo, como reclaman algunos estudiosos, quizás podrían verse las cosas con más claridad.

\section{Referencias bibliográficas}

Agustín, Laura M. (2008). «Trabajo y ciudadanía: movimientos pro derechos de las trabajadoras del sexo». En: Solana, José Luis y Acién, Estefanía (eds.). Los retos de la prostitución: Estigmatización, derechos y respeto. Granada: Comares.

- (2009). «The conundrum of women's agency: migration and the sex industry». En: Campbell, Rosie y O’Neill, Maggie (eds.). Sex Work Now. Cullompton: Willan.

Ballester, Lluís; Orte, Carme; Perelló, Jaume y JordÀ, Maria M. (2003). «Estudi sobre la prostitució femenina a Mallorca». En: ApARISI, Elvira et al. La prostitució femenina a les Balears. Palma: Lleonard Muntaner. 
Brufao, Pedro (2008). Prostitución y políticas públicas: Entre la reglamentación, la legalización y la abolición. Madrid: Fundación Alternativas.

Carchedi, Francesco y Tola, Vittoria (a cargo de) (2008). All'aperto e al chiuso. Prostituzione e tratta: $i$ nuovi dati del fenomeno, i servizi sociali, le normative di riferimento. Roma: Ediesse.

Chapkis, Wendy (1997). Live Sex Acts: Women Performing Erotic Labour. Nueva York: Routledge.

Colectivo IOÉ y Agustín, Laura M. (2001). «Mujeres inmigrantes ocupadas en servicios sexuales». En: Colectivo IOÉ. Mujer, inmigración y trabajo. Madrid: Ministerio de Trabajo y Asuntos Sociales.

Comisión Mixta de los Derechos de la Mujer y de la Igualdad de OportuniDADES (2007). «Informe de la ponencia sobre la situación actual de la prostitución en nuestro país». Boletín Oficial de las Cortes Generales. Sección "Cortes Generales», núm. 379, 24 de mayo.

DAY, Sophie (1996). "The law and the market: Rhetorics of exclusion and inclusion among London prostitutes». En Harris, Olivia (ed.). Inside and Outside the Law. Londres: Routledge.

Doezema, Jo (1998). «Forced to Choose: Beyond the Voluntary v. Forced Prostitution Dichotomy». En: Kempadoo, Kamala y Doezema, Jo (eds.). Global Sex Workers: Rights, Resistance and Redefinition. Londres: Routledge.

- (2000). «Loose women or lost women: the re-emergence of the myth of white slavery in contemporary discourses of trafficking in women». Gender Studies, 18 (1), 23-50.

Fita, Fernando (2007). «El trabajo sexual en la doctrina judicial española». En: Serra, Rosario (coord.). Prostitución y trata: Marco jurídico y régimen de derechos. Valencia: Tirant lo Blanch.

Gall, Gregor (2006). Sex Worker Union Organizing: An International Study. Basingstoke: Palgrave MacMillan.

Gregorio, Carmen y Ramírez, Ángeles (2000). «¿En España es diferente...?: Mujeres inmigrantes dominicanas y marroquíes». Papers, 60, 257-273.

GuY, Donna J. (1992). "White slavery", citizenship and nationality in Argentina». En: Parker, Andrew; Russo, Mary; Sommer, Doris y Yaeger, Patricia (eds.). Nationalisms and Sexualities. Nueva York: Routledge.

INGECON (2007). Estudio sobre la explotación sexual de las mujeres, con referencia al tráfico ilegal: Documento de síntesis, 2005-2006. Madrid: Instituto de la Mujer.

Juliano, Dolores (2003). «Prostitución: el modelo de control sexual femenino a partir de sus límites». En: Osborne, Raquel y Guasch, Óscar (comps.). Sociología de la sexualidad. Madrid: CIS-Siglo XXI.

Kempadoo, Kamala (1998). «Introduction: Globalizing Sex Workers' Rights». En: Kempadoo, Kamala y Doezema, Jo (eds.). Global Sex Workers: Rights, Resistance and Redefinition. Londres: Routledge.

Kinnell, Hilary (2009). «Clients of female sex workers: men or monsters?». En: Campbell, Rosie y O’Neill, Maggie (eds.). Sex Work Now. Cullompton: Willan.

Malgesini, Graciela (coord.) (sin fecha). Impacto de una posible normalización profesional de la prostitución en la viabilidad y sostenibilidad futura del sistema de pensiones de protección social: Informe ESCODE 2006. Madrid: Ministerio de Trabajo y Asuntos Sociales. Secretaría de Estado de la Seguridad Social. [En línea]

Mathieu, Lilian (2007). La condition prostituée. París: Textuel. 
Mckeganey, Neil y Barnard, Marina (1997). Sex Work on the Streets: Prostitutes and their Clients. Buckingham: Open University Press.

Meneses, Carmen (dir.) (2003). Perfil de la prostitución callejera: Análisis de una muestra de personas atendidas por APRAM. Madrid: Universidad Pontificia de Comillas.

O'Connell Davidson, Julia (2003). “"Sleeping with the enemy”?: Some Problems with Feminist Abolitionist Calls to Penalise those who Buy Commercial Sex». Social Policy \& Society, 2 (1), 55-63.

Portes, Maïko-David (2007). Prostitution et politiques européennes: Pour une approche anthropologique du droit. París: L'Harmattan.

QUESTDATA (2004). A prostitución feminina na Comunidade Autónoma de Galicia. Consellería de Familia, Xuventude, Deporte e Voluntariado. Xunta de Galicia.

SANCHIs, Enric (2008). «La ponencia sobre la prostitución en España». Claves de razón práctica, 187, 18-24.

SANCHIS, Enric y SERra, Inmaculada (2009). "Il mercato della prostituzione femminile in Spagna: Una valutazione a partire dal caso valenzano». La Critica Sociologica, 172 (4), 61-80. [Versión ampliada en Política y Sociedad, 48 (1), 2011, 175-192.]

SAnders, Teela (2008). Sex Work. A Risky Business. Cullompton: Willan.

SERra, Inmaculada (coord.) (2008). La prostitución femenina en la Comunidad Valenciana. Valencia: Conselleria de Benestar Social. [Fotocopiado]

Solana, José Luis (2007). "Movimientos migratorios, trabajadoras inmigrantes y empleo en la prostitución». Documentación Social, 144, 37-57.

- (2008). «El informe de la ponencia para el estudio de la situación actual de la prostitución en España: Análisis, comentarios y evaluación». En: Solana, José Luis y AcıÉn, Estefanía (eds.). Los retos de la prostitución: Estigmatización, derechos y respeto. Granada: Comares.

Walkowitz, Judith (1994). City of Dreadful Delight: Narratives of Sexual Danger in Late-Victorian London. Londres: Virago. 